\title{
Economic evaluation of posaconazole versus standard azole therapy as prophylaxis against invasive fungal infections in patients with prolonged neutropenia in Canada
}

\author{
Amir A Tahami Monfared MSc PhD ${ }^{1}$, Amy K O'Sullivan PhD², \\ Coleman Rotstein MD FRCPC ${ }^{3}$, George Papadopoulos BS(Hons) ${ }^{4}$
}

\begin{abstract}
AA Tahami Monfared, AK O'Sullivan, C Rotstein, $\mathrm{G}$ Papadopoulos. Economic evaluation of posaconazole versus standard azole therapy as prophylaxis against invasive fungal infections in patients with prolonged neutropenia in Canada. Can J Infect Dis Med Microbiol 2012;23(2):59-64.
\end{abstract}

INTRODUCTION: Posaconazole prophylaxis in high-risk neutropenic patients prevents invasive fungal infection (IFI). An economic model was used to assess the cost effectiveness of posaconazole from a Canadian health care system perspective.

METHODS: A decision-analytic model was developed based on data from a randomized trial comparing posaconazole with standard azole (fluconazole or itraconazole) therapy. The model was extrapolated to a lifetime horizon using one-month Markov cycles; lifetime survival was specific to the underlying disease. Drug and treatment costs associated with IFI were estimated using published literature. The model was used to estimate total costs, IFIs avoided, life-years gained and the incremental cost-effectiveness ratio of posaconazole versus standard azole therapy, in 2007 Canadian dollars.

RESULTS: Based on the clinical trial data, posaconazole was associated with fewer cases of IFI ( 0.05 versus $0.11 ; \mathrm{P}=0.003)$, increased life-years (2.52 years versus 2.43 years) and slightly lower costs $(\$ 6,601$ versus $\$ 7,045)$ per patient relative to standard azole therapy over a lifetime horizon. Higher acquisition costs for posaconazole were offset by IFIassociated inpatient costs for those prophylaxed with standard azoles. Probabilistic sensitivity analysis indicated a 59\% probability that posaconazole was cost-saving versus standard azole therapy and a $96 \%$ probability that the incremental cost-effectiveness ratio for posaconazole was at or below the $\$ 50,000$ per life-year saved threshold.

DISCUSSION: In Canada, posaconazole appears to be cost-saving relative to standard azole therapy in IFI prevention among high-risk neutropenic patients.

Key Words: Canada; Cost-effectiveness; Neutropenia; Posaconazole; Prophylaxis

nvasive fungal infections (IFIs) cause significant morbidity and mor-
tality and are difficult to treat once established (1-3). Causative
pathogens seen with increasing frequency in recent years include
Candida and Aspergillus species and the Zygomycetes $(4,5)$. Patients
with cancer are at particularly high risk for IFI because of intensive
chemotherapy resulting in neutropenia and other immunosuppressive
treatments (3-6). IFI-associated morbidity can delay or prevent treat-
ment of a patient's underlying malignancy (7). Furthermore, retro-
spective data on approximately eight million hospitalizations showed
that candida and aspergillus infections resulted in increased treatment
costs of approximately US $\$ 45,616$ and US $\$ 25,128$, respectively, in
L'évaluation économique du posaconazole par rapport à une thérapie standard à l'azole en prophylaxie d'infections fongiques invasives chez des patients du Canada ayant une neutropénie prolongée

INTRODUCTION : La prophylaxie au posaconazole chez les patients neutropéniques à haut risque prévient l'infection fongique invasive (IFI). Les chercheurs ont utilisé un modèle économique pour évaluer le rapport coût-efficacité du posaconazole dans un système de santé canadien.

MÉTHODOLOGIE : Les chercheurs ont mis au point un modèle de décision analytique fondé sur des données tirées d'un essai aléatoire comparant le posaconazole à un traitement standard à l'azole (fluconazole ou itraconazole). Ils ont extrapolé le modèle à l'horizon d'une vie au moyen de modèles de Markov sur un mois. La survie longitudinale dépendait de la maladie sous-jacente. Ils ont estimé les coûts des médicaments et des traitements associés à l'IFI d'après des publications scientifiques et utilisé le modèle pour estimer les coûts totaux, les IFI évitées, les années de vie gagnées et le rapport coût-efficacité incrémentiel (RCEI) du posaconazole par rapport à une thérapie standard à l'azole, en dollars canadiens de 2007. RÉSULTATS : D'après les données d'essai clinique, le posaconazole s'associait à un moins grand nombre de cas d'IFI $(0,05$ par rapport à 0,11 ; $\mathrm{P}=0,003)$, à l'augmentation des années de vie ( 2,52 ans par rapport à 2,43 ans) et à des coûts légèrement moins élevés (6 601 \$ par rapport à 7045 \$) par patient par rapport à la thérapie standard à l'azole sur l'horizon d'une vie. Les coûts d'acquisition plus élevés du posaconazole étaient contrebalancés par les coûts d'hospitalisation des patients en raison d'une IFI qui recevaient une prophylaxie standard aux azoles. D'après l'analyse de sensibilité probabiliste, il y avait $59 \%$ de probabilité que le posaconazole soit plus économique que la thérapie standard à l'azole et $96 \%$ de probabilité que le RCEI du posaconazole corresponde ou soit inférieur au seuil de 50000 \$ par année de vie épargnée.

EXPOSÉ : Au Canada, le posaconazole semble être économique par rapport à la thérapie standard à l'azole pour prévenir l'IFI chez les patients neutropéniques à haut risque.

high-risk patients compared with matched control patients with no IFI (8). Specifically, in the present study, patients with hematological malignancies had costs associated with any IFI of approximately US\$37,046 more than patients without an IFI.

Antifungal prophylaxis has been recommended for patients with cancer at high risk for IFI by such organizations as the National Comprehensive Cancer Network (9), the Infectious Diseases Society of America (1), the American Society for Blood and Marrow Transplantation (10) and the European Conference on Infections in Leukemia (11). Current antifungal agents with the potential to prevent fungal infections include amphotericin B compounds, azoles

\footnotetext{
${ }^{1}$ Merck Eु Co Inc, Kirkland, Quebec; ${ }^{2} i 3$ Innovus, Medford, Massachusetts, USA; ${ }^{3}$ University of Toronto, University Health Network,

Toronto, Ontario; ${ }^{4}$ Merck $\mathcal{B}$ Co Inc, Whitehouse Station, New Jersey, USA

Correspondence and reprints: Dr AA Tahami Monfared, Merck E Co Inc, 16750 Route Transcanadienne, Kirkland, Quebec H9H 4 M7.

Telephone 514-428-8804, fax 514-428-7471, e-mail amir.tahami@email.com
} 


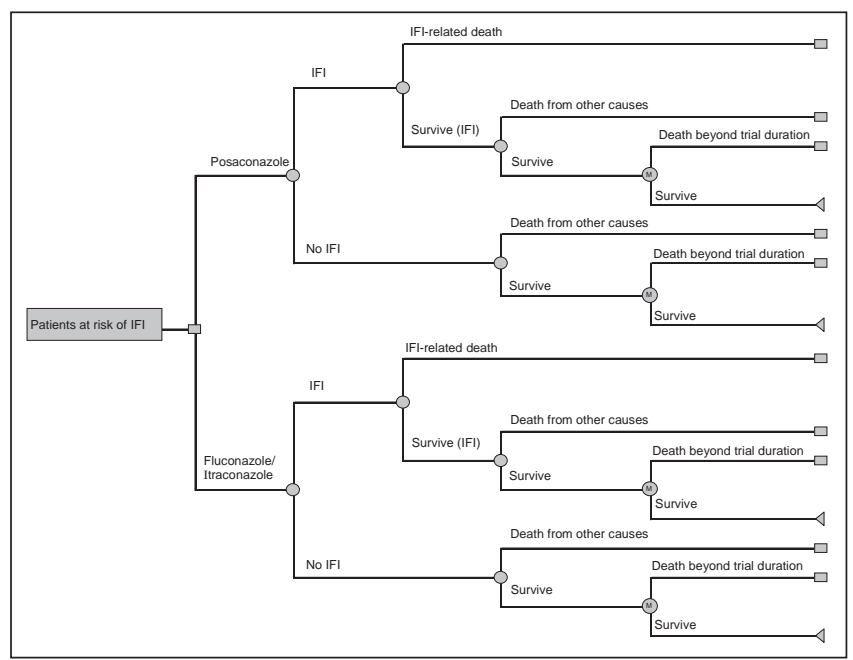

Figure 1) Model structure. IFI Invasive fungal infection; M Monte Carlo

(fluconazole, itraconazole, voriconazole and posaconazole) and echinocandins (caspofungin, micafungin and anidulafungin). The National Comprehensive Cancer Network has advocated extended-spectrum antifungal prophylaxis and has recommended that neutropenic patients with acute myeloid leukemia (AML) or myelodysplastic syndrome (MDS) receive prophylaxis with a mould-active antifungal agent (posaconazole as category 1 ; voriconazole or amphotericin B as category 2B) (9). In contrast, the Infectious Diseases Society of America guidelines are not quite as encompassing; for the management of invasive aspergillosis (IA), the guidelines recommend primary prophylaxis with posaconazole for hematopoietic stem cell transplantation recipients with graft-versus-host disease and for neutropenic patients with AML or MDS who are at risk for IA. Alternative preventive pharmacotherapies for IA are itraconazole (intravenous or oral) and micafungin (1).

Posaconazole is an extended-spectrum oral triazole. It has demonstrated efficacy against various pathogenic moulds and yeasts, including those resistant to other antifungal therapies (12-16) and is approved for use in various jurisdictions for prophylaxis of aspergillus and candida infections in high-risk patients with prolonged neutropenia and hematopoietic stem cell transplantation recipients (17-19).

In a pivotal, randomized clinical trial, posaconazole demonstrated superior efficacy compared with standard azole therapy with fluconazole or itraconazole in preventing proven and probable IFIs (occurrence in $2 \%$ versus $8 \%$ of patients, respectively) and reducing overall mortality in high-risk neutropenic patients who received cytotoxic chemotherapy for AML or MDS (20). Significantly fewer patients in the posaconazole group had IA ( $1 \%$ versus $7 \% ; \mathrm{P}<0.001$ ), and survival was significantly longer among posaconazole recipients compared with recipients of fluconazole or itraconazole $(\mathrm{P}=0.04)(20)$.

Despite the demonstrated clinical superiority over fluconazole and itraconazole, concerns abound regarding the high drug acquisition cost for posaconazole. Notwithstanding these concerns, studies have demonstrated that posaconazole is a cost-effective or cost-saving alternative to itraconazole and fluconazole in patients with AML or MDS, and chemotherapy-induced neutropenia in the United States (USA) $(21,22)$ and the Netherlands (23). The Netherlands study (23) reported a 90\% probability that the cost increase per quality-adjusted life-year with posaconazole was less than $€ 20,000$. A study conducted in the USA (21) reported a $96 \%$ probability that the incremental cost-effectiveness ratio (ICER) for posaconazole was $\leq \$ 50,000$ per life-year saved (LYS) and that there was a $73 \%$ probability that posaconazole was cost-saving compared with fluconazole or itraconazole. In another American analysis (22), posaconazole prophylaxis was associated with lower overall treatment costs compared with patients with prolonged neutropenia who were administered prophylaxis with fluconazole or itraconazole.

The aim of the present study was to apply a decision-analytic model based on data from a randomized prophylactic clinical trial
TABLE 1

Model parameters and data sources

\begin{tabular}{|c|c|c|}
\hline Model parameter & Estimate & $\begin{array}{l}\text { Data source, } \\
\text { author, year (reference) }\end{array}$ \\
\hline \multicolumn{3}{|l|}{ Efficacy of prophylaxis } \\
\hline $\begin{array}{l}\text { Probability of IFI with fluconazole/ } \\
\text { itraconazole }\end{array}$ & 0.11 & Cornely et al, 2007 (20) \\
\hline Probability of IFI with posaconazole & 0.05 & Cornely et al, 2007 (20) \\
\hline \multicolumn{3}{|l|}{ Survival after prophylaxis } \\
\hline Probability of IFI-related death, given IFI & 0.43 & Cornely et al, 2007 (20) \\
\hline Probability of other death within 100 days & 0.15 & Cornely et al, 2007 (20) \\
\hline Relative survival for AML after 100 days & 0.21 & $\begin{array}{l}\text { CSS, } 2009 \text { (24); } \\
\text { SEER } 2006(25)\end{array}$ \\
\hline Relative survival for MDS after 100 days & 0.08 & Kantarjian et al, 2006 (36) \\
\hline \multicolumn{3}{|l|}{ Costs $^{\star}, \$$} \\
\hline \multicolumn{3}{|l|}{ Cost of treating an $|\mathrm{FI}|^{\star}$} \\
\hline Candidiasis & 52,618 & OCCI 2007/2008 (26) \\
\hline Aspergillosis & 61,198 & OCCI 2007/2008 (26) \\
\hline \multicolumn{3}{|l|}{ Weighted cost of an $\mathrm{IFI}^{\star \dagger}$} \\
\hline Fluconazole/itraconazole trial arm & 59,378 & Cornely et al, 2007 (20) \\
\hline Posaconazole trial arm & 55,069 & Cornely et al, 2007 (20) \\
\hline \multicolumn{3}{|l|}{ Drug costs per day* } \\
\hline Fluconazole & 22.19 & RAMQ \\
\hline Itraconazole & 14.00 & RAMQ \\
\hline Posaconazole & 141.14 & RAMQ \\
\hline \multicolumn{3}{|l|}{ Duration of prophylaxis, days, mean \pm SD } \\
\hline Fluconazole & $24 \pm 16$ & Cornely et al, 2007 (20) \\
\hline Itraconazole & $29 \pm 21$ & Cornely et al, 2007 (20) \\
\hline Posaconazole & $29 \pm 21$ & Cornely et al, 2007 (20) \\
\hline Discount rate, \% & 5 & CADTH Guidelines (37) \\
\hline
\end{tabular}

${ }^{*}$ Canadian dollars; ${ }^{\dagger}$ Weighted according to the incidence of candidiasis and aspergillosis reported in the posaconazole and control arm from the randomized trial. AML Acute myeloid leukemia; CADTH Canadian Agency for Drugs and Technologies in Health; CSS Cancer Survival Statistics (Statistics Canada); IFI Invasive fungal infection; MDS Myelodysplastic syndrome; OCCI Ontario Case Costing Initiative; RAMQ Régie de l'assurance maladie du Québec; SEER Surveillance, Epidemiology, and End Results

comparing posaconazole with fluconazole or itraconazole (standard azole therapy) (20) and to evaluate the cost effectiveness of posaconazole compared with fluconazole or itraconazole from a Canadian health care perspective.

\section{METHODS}

A decision-analytic model was developed to estimate the cost effectiveness of antifungal prophylaxis therapy among patients with AML or MDS at high risk for IFI caused by chemotherapy-induced neutropenia (Figure 1).

Patients in the model were assumed to receive prophylaxis with posaconazole or standard azole therapy (fluconazole or itraconazole) for the prevention of IFIs, as reported in the clinical trial of Cornely et al (20). This was a randomized, multicentre trial in which prophylaxis was administered with each chemotherapy cycle and was continued until recovery from neutropenia and complete remission, or occurrence of an IFI for up to 12 weeks following randomization, whichever came first. Patients were followed for a total of 100 days after randomization.

A hybrid model consisting of a decision tree and a Markov model was constructed to compare prophylaxis strategies. Patients at risk of IFI enter the decision tree and receive prophylaxis with either posaconazole or standard azole therapy (Figure 1); distributions of patients receiving fluconazole and itraconazole in the comparator group were assumed to be the same as those in this trial (ie, $81 \%$ fluconazole and 19\% itraconazole) (20). 
TABLE 2

Cost effectiveness of posaconazole versus standard azoles in the prophylaxis of invasive fungal infection (IFI) among highrisk neutropenic patients

\begin{tabular}{|c|c|c|c|c|c|c|c|c|c|c|}
\hline Prophylaxis & $\begin{array}{c}\text { Total cost*, } \\
\$\end{array}$ & $\begin{array}{c}\text { IFI inpatient } \\
\text { costs* }^{*} \$\end{array}$ & $\begin{array}{c}\text { Drug costs*, } \\
\$\end{array}$ & $\begin{array}{c}\text { Cases of } \\
\text { IFI }\end{array}$ & $\begin{array}{c}\text { Cases of } \\
\text { IFI avoided }\end{array}$ & LY & LYS & $\begin{array}{c}\text { Incremental } \\
\text { cost* }^{*} \$\end{array}$ & $\begin{array}{l}\text { Cost per IFI } \\
\text { avoided*, \$ }^{\text {avide }}\end{array}$ & $\begin{array}{l}\text { Cost per } \\
\text { LYS*, \$ }\end{array}$ \\
\hline Fluconazole/itraconazole & 7,045 & 6,532 & 514 & 0.11 & - & 2.43 & - & - & - & - \\
\hline Posaconazole & 6,601 & 2,522 & 4079 & 0.05 & 0.06 & 2.52 & 0.09 & 444 & Cost saving & Cost saving \\
\hline
\end{tabular}

*2007 Canadian dollars. LY Life-years; LYS LY saved

Clinical events were modelled during the study period using data from the clinical trial (Table 1) (20) with chance nodes reflecting the probabilities of IFI, IFI-related death and death from other causes; survival beyond 100 days was modelled by extending the decision tree with one-month Markov cycles that extrapolate survival to a lifetime horizon.

Patients who experience an IFI are subsequently at risk of death from IFI. Patients who do not have an IFI, as well as those who survive an IFI, are at risk of short-term (ie, within 100 days) death from causes unrelated to IFI. Patients who survive the 100-day period following initiation of prophylaxis enter a Markov model in which their monthly risk of death is specific to the underlying condition (ie, AML or MDS) but independent of whether they previously had an IFI. Lifetime survival beyond the trial follow-up period was estimated for AML patients based on Cancer Survival Statistics (Statistics Canada, Ottawa, Ontario) (24), as well as Surveillance, Epidemiology, and End Results (SEER) data from the National Cancer Institute (25). This estimate was applied to age-specific death rates for the general population obtained from Statistics Canada's Life Tables.

Costs of IFI prophylaxis were estimated using drug acquisition costs. The costs of managing IFIs associated with invasive aspergillosis and candidiasis were obtained from the Ontario Case Costing Initiative (OCCI) database (26). The OCCI database is a record-specific costing database for acute care inpatients and day surgery patients admitted to participating hospitals. A costing analysis tool allows the user to select the diagnostic codes and have the corresponding average cost calculated on the OCCI website. An incidence-based approach to estimating the costs of IFIs that occur within the trial period was used. For the base case analysis, the cost of treating an IFI was weighted based on the incidence of invasive aspergillosis and invasive candidiasis reported for each arm in the pivotal trial (20); the posaconazole group had a lower incidence of breakthrough IFIs compared with standard azole therapy ( 0.29 versus 0.79 , respectively).

The model was used to estimate total costs, IFIs avoided, life-years gained and ICER of posaconazole compared with standard azole therapy from a third-party perspective in 2007 Canadian dollars. One-way sensitivity analyses and second-order probabilistic Monte Carlo sensitivity analysis were conducted to assess the robustness of model results and the effects of parameter uncertainty on the study findings, particularly as related to treatment efficacy and IFI costs.

\section{RESULTS}

In the trial published by Cornely et al (20), AML was the primary diagnosis in $86 \%$ of patients and MDS was the primary diagnosis in $14 \%$ of patients. The approximate average age was 50 years, and $53 \%$ of patients were male.

Among a population of neutropenic patients at high risk, the model suggests that posaconazole is associated with fewer IFIs, increased lifeyears and lower costs per patient than standard azole therapy over a lifetime horizon (Table 2 and Figure 2). Posaconazole was associated with fewer cases of IFIs: 0.05 versus $0.11 ; \mathrm{P}=0.003$ (0.06 IFI avoided); increased life-years: 2.52 versus 2.43 (0.09 LYS per patient); and slightly lower total costs: $\$ 6,601$ versus $\$ 7,045$ ( $\$ 444$ lower). The higher acquisition cost of posaconazole $(\$ 4,079$ versus $\$ 514)$ was offset by higher IFI-associated inpatient costs for patients prophylaxed with fluconazole and itraconazole $(\$ 6,532$ versus $\$ 2,522)$.

All-cause mortality rates within the clinical trial were $16 \%$ (posaconazole) versus 22\% (fluconazole or itraconazole) $(\mathrm{P}=0.048)$

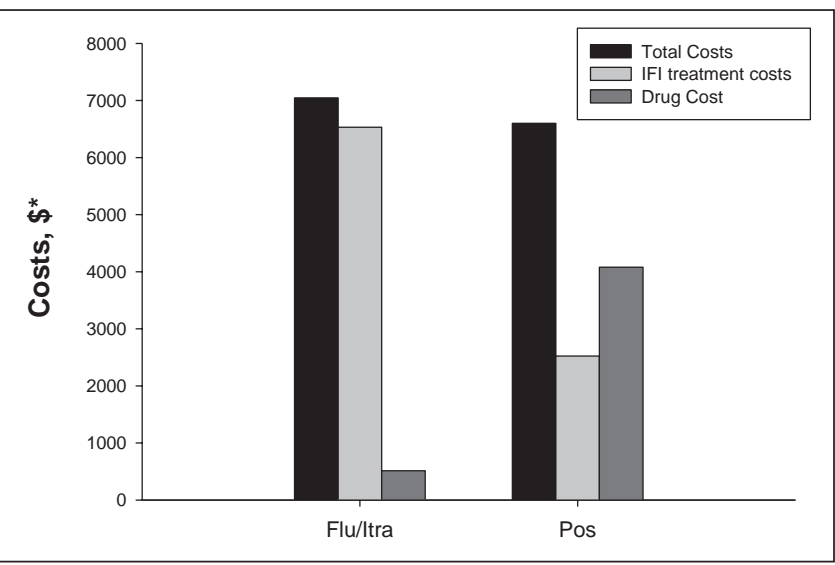

Figure 2) Invasive fungal infection (IFI) inpatient treatment costs among high-risk neutropenic patients. *2007 Canadian dollars. Flu Fluconazole; Itra Itraconazole; Pos Posaconazole

(20). There were significantly fewer IFI-related deaths $(\mathrm{P}=0.01)$ in the posaconazole group (five of 304 [1.6\%]) compared with the fluconazole or itraconazole group (16 of 298 [5.4\%]) (20). The economic model used conservative aggregate assumptions regarding IFI-related mortality. Total cost and mortality within the 100 -day trial period in the economic model remained lower with posaconazole than with standard azole therapy.

Results from one-way sensitivity analyses on the risk of IFIs with posaconazole and fluconazole or itraconazole, the cost of treating an IFI and the costs of prophylaxis with fluconazole or itraconazole are presented in Table 3. One-way sensitivity analyses indicated that the posaconazole cost-effectiveness ratio was most sensitive to the risk of IFI, followed by the mean duration of posaconazole prophylaxis. Varying the efficacy of posaconazole using the $95 \%$ CI for the difference between the prophylaxis groups from the trial, the ICER for posaconazole ranged from being cost-saving to $\$ 35,443$ per LYS relative to fluconazole or itraconazole.

The probabilistic sensitivity analysis results showed that there was a 59\% chance that posaconazole was cost-saving compared with standard azole therapy and that there was a $96 \%$ chance that the ICER for posaconazole is equal to or less than the $\$ 50,000$ per LYS threshold (Figures 3 and 4).

\section{DISCUSSION}

Posaconazole is clinically more effective than standard azole therapy (fluconazole or itraconazole) in preventing IFIs and reducing overall mortality in neutropenic patients at high risk for such an infection (20). The IFI probability for the fluconazole or itraconazole group (0.11) reflects the observed rates in clinical practice and is within the range of other published estimates in patients with hematological malignancies ( $6 \%$ to $12 \%)(4,27)$. The improved clinical outcomes seen with posaconazole in the Cornely et al (20) trial appear to translate into cost savings despite its higher acquisition cost.

Cost-effectiveness analyses indicated that posaconazole was cost effective or cost saving compared with itraconazole and fluconazole for the prevention of IFIs among high-risk AML and MDS patients undergoing induction chemotherapy in the USA and the Netherlands $(21,23)$. 
TABLE 3

Univariate sensitivity analyses of the cost effectiveness of posaconazole versus standard azoles in the prophylaxis of invasive fungal infection (IFI) among high-risk neutropenic patients

\begin{tabular}{|c|c|c|c|c|c|c|}
\hline \multirow[b]{2}{*}{ Parameter } & \multirow[b]{2}{*}{ Base case } & \multirow[b]{2}{*}{ Low value* } & \multirow[b]{2}{*}{ High value* } & \multicolumn{2}{|c|}{ ICER (\$LYS) $^{\dagger}$} & \multirow[b]{2}{*}{ Magnitude of variation ${ }^{\dagger}$} \\
\hline & & & & Lower & Upper & \\
\hline Risk of IFI on posaconazole & 0.05 & 0.0024 & 0.0883 & Dominant & 35,443 & $>35,443$ \\
\hline Risk of IFI on fluconazole/itraconazole & 0.11 & 0.0825 & 0.1375 & 8,315 & Dominant & $>8,315$ \\
\hline \multicolumn{7}{|l|}{ Cost of $\mathrm{IFI}^{\dagger}, \$$} \\
\hline Candidiasis/aspergillosis & $55,069 / 59,378$ & 55,069 & 59,378 & 335 & Dominant & $>335$ \\
\hline Costs of fluconazole/itraconazole ${ }^{\dagger}, \$$ & $22.19 / 14.00$ & $16.64 / 10.50$ & $27.74 / 17.50$ & Dominant & Dominant & - \\
\hline Duration of posaconazole prophylaxis, days & 28.9 & 7.8 & 50 & Dominant & 28,308 & $>28,308$ \\
\hline Probability of patients receiving itraconazole & 0.19 & zero & 1.00 & Dominant & Dominant & - \\
\hline
\end{tabular}

${ }^{*}$ Ranges estimated as $\pm 25 \%$ of model values, except for risk of IFI on posaconazole, which was estimated using the $95 \%$ confidence interval for the difference in risk between the posaconazole and standard azole groups, and duration of posaconazole prophylaxis that were derived from the Cornely et al trial (20); ${ }^{\dagger}$ Canadian dollars. ICER Incremental cost-effectiveness ratio; LYS Life-years saved

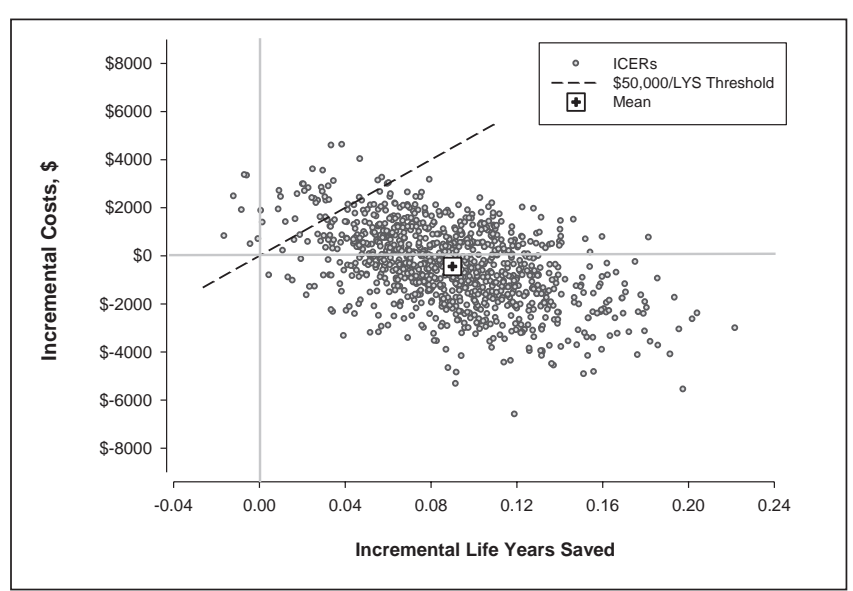

Figure 3) Results from second-order probabilistic Monte Carlo sensitivity analysis. *Canadian dollars. ICER Incremental cost-effectiveness ratio; LYS Life-years saved

Results from the current analysis indicate that posaconazole prophylaxis is cost effective from the Canadian health care perspective and is likely to be cost saving compared with standard azoles in patients with AML and MDS who are undergoing intensive induction chemotherapy for AML.

Total cost savings were $\$ 6,601$ (posaconazole) versus $\$ 7,045$ (standard azoles). In one-way sensitivity analyses, the ICER was most sensitive to the risk of IFI, followed by mean duration of posaconazole prophylaxis. Results from the probabilistic sensitivity analysis indicated that posaconazole has a 59\% chance of being cost-saving compared with standard azoles and that there was a $96 \%$ chance that the ICER for posaconazole was equal to or less than the $\$ 50,000$ per LYS threshold. Posaconazole prevented more IFIs than the comparator regimens (IFI avoided: 0.06).

Posaconazole prophylaxis for the prevention of IFIs in immunocompromised patients has also been recognized recently by a number of governmental bodies as cost effective. The Scottish Medicines Consortium and the Australian Pharmaceutical Benefits Advisory Committee have acknowledged the clinical and cost-effectiveness evidence for posaconazole compared with fluconazole and itraconazole $(28,29)$. However, not all jurisdictions concur. In a recent Common Drug Review of posaconazole by the Canadian Agency for Drugs and Technologies in Health, IFI prophylaxis with posaconazole was not recommended (19). The Common Drug Review believed that the supporting data were not robust enough because in the clinical trial published by Cornely et al (20), too few patients were randomized to receive itraconazole to provide a meaningful comparison between posaconazole and itraconazole (19). A head-to-head direct comparison of posaconazole and itraconazole would indeed be of interest; however, the aforementioned clinical trial published by Cornely et al (20) simulated clinical practice where patients were randomly assigned

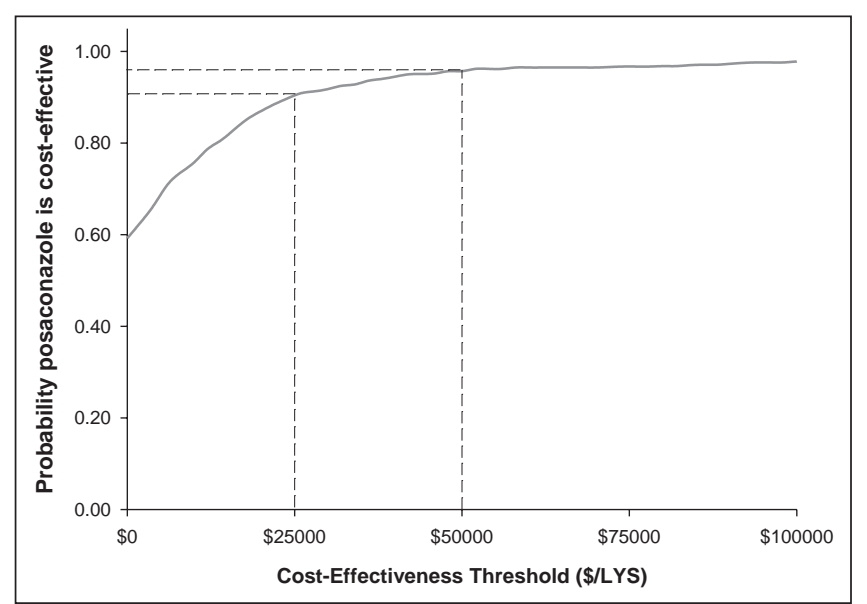

Figure 4) Cost-effectiveness acceptability curve. LYS Life-years saved

to receive either posaconazole or standard azole therapy according to investigators' institutional standard protocol. The low number of patients receiving itraconazole, as stated by the study authors (20), reflects the fact that fluconazole had become the standard of care for antifungal prophylaxis in patients with AML undergoing induction chemotherapy. Although itraconazole also reduces the incidence of proven IFIs (30), it has not conferred a significant survival benefit over fluconazole in large trials, and it has been associated with greater toxicity with no additional clinical benefit (31-33).

It has been demonstrated that hospital length of stay costs are the single most important issue contributing to higher costs in costeffectiveness studies. Our analysis has the limitation that the duration of hospitalization was not measured in the Cornely et al study (20); therefore, a reduced duration of hospitalization (and an associated reduction in costs) in posaconazole-treated patients was assumed to be similar to that observed in the OCCI database $(19,26)$. Increased hospitalization costs due to IFI have been widely reported. A study of almost 12,000 patients with IFIs and approximately the same number of control patients (matched by age, sex and either high-risk group or primary diagnosis) without IFIs reported that relative to the control group, patients with an IFI stayed an average of 11.4 days longer in hospital $(\mathrm{P}<0.001)$ (8). Dasbach et al (34) estimated costs of aspergillosisrelated hospitalization in 1996 from the Nationwide Inpatient Sample of the Healthcare Cost and Utilization Project in patients with a range of underlying conditions; aspergillosis led to an average hospital stay of 18.8 days (compared with 5.0 days in matched patients without aspergillosis; $\mathrm{P}<0.05)$. Another American study, which estimated the 1998 incidence and direct patient costs associated with IFIs, concluded that the incremental average hospitalization costs per patient attributable to aspergillosis and candidiasis were significantly greater than those 
without infection and that drug costs accounted for only $17 \%$ of total hospitalization costs (35). The study reported that transplant recipients had the highest mean additional costs attributable to IFI, an additional US $\$ 83,949$ for aspergillosis $(\mathrm{P}=0.0096)$ and US $\$ 47,221$ for candidiasis $(\mathrm{P}<0.0001)$, compared with matched patients without IFI (35). However, these studies may suffer from lack of specificity of costs related to IFIs in patients with AML and MDS.

Beyond the fact that the Cornely et al trial (20) was not powered to detect differences between posaconazole and fluconazole or itraconazole separately, there are a number of other limitations associated with the present study. Event rates were derived from a single, large, randomized clinical trial (20). Although additional phase 3 or 4 randomized trial results are desirable, we do not know whether a replication trial to confirm safety and efficacy will be performed. However, clinical evidence demonstrated efficacy of posaconazole in preventing IFIs and reducing the rate of deaths related to such pathogens (12-16). Treatment costs can vary greatly; however, this model analysis assumes that the costs of treating the underlying disease are the same between both groups. The costs associated with treating an IFI were not reported separately according to underlying disease; there was extrapolation of data from the 100-day clinical study follow-up to a lifetime horizon using one-month Markov cycles until all patients had died, and IFI case fatality rates were pooled and assumed to be equal for patients in both treatment groups. In addition, treatment costs associated with adverse events were not included in the model. This assumption, however, was deemed appropriate because treatment-related adverse events were relatively low and unlikely to affect the overall results and conclusion. Finally, it is important to note that subsequent antifungal therapies for treatment failures were not accounted for in this model because of the lack of availability of these data.

\section{CONCLUSION}

Results from the probabilistic, sensitivity analysis in the present economic evaluation from a Canadian health care perspective indicated that there is a $59 \%$ chance that posaconazole is cost-saving compared with standard azoles and a $96 \%$ chance that the ICER for posaconazole is equal to or less than the $\$ 50,000$ per LYS threshold. Posaconazole appears to be a cost-effective agent for the prevention of fungal infections in high-risk neutropenic patients in Canada.

CONFLICT OF INTEREST: This study was funded by ScheringPlough Canada Inc. Dr Rotstein has received research grants or support from Astellas, Basilea, Johnson \& Johnson, Merck/Schering-Plough and Pfizer-Wyeth. He is also a consultant to and on the speakers bureaus of Astellas, Bayer, Merck/Schering-Plough and Pfizer-Wyeth.

ACKNOWLEDGEMENTS: The authors thank Sheena Hunt PhD in association with ApotheCom, for providing editorial assistance that was funded by Schering-Plough (now Merck \& Co, Inc) for the authors' original work.

\section{REFERENCES}

1. Walsh TJ, Anaissie EJ, Denning DW, et al. Treatment of aspergillosis: Clinical practice guidelines of the Infectious Diseases Society of America. Clin Infect Dis 2008;46:327-60.

2. Pfaller MA, Diekema DJ. Epidemiology of invasive candidiasis: A persistent public health problem. Clin Microbiol Rev 2007;20:133-63.

3. Patterson TF. Invasive mycoses: Management and unmet medical needs. Curr Opin Infect Dis 2001;14:669-71.

4. Pagano L, Caira M, Candoni A, et al. The epidemiology of fungal infections in patients with hematologic malignancies: The SEIFEM-2004 study. Haematologica 2006;91:1068-75.

5. Warnock DW. Trends in the epidemiology of invasive fungal infections. Japan J Med Mycol 2007;48:1-12.

6. Ruping MJ, Vehreschild JJ, Cornely OA. Patients at high risk of invasive fungal infections: When and how to treat. Drugs 2008;68:1941-62.
7. Mahfouz T, Anaissie E. Prevention of fungal infections in the immunocompromised host. Curr Opin Investig Drugs 2003:4:974-90.

8. Menzin J, Meyers JL, Friedman M, et al. Mortality, length of hospitalization, and costs associated with invasive fungal infections in high-risk patients. Am J Health Syst Pharm 2009;66:1711-7.

9. National Comprehensive Cancer Network. NCCN Clinical Practice Guidelines in Oncology: Prevention and Treatment of Cancer-Related Infections. V.2.2009. < www.nccn.org> (Accessed July 14, 2009).

10. Tomblyn M, Chiller T, Einsele H, et al. Guidelines for preventing infectious complications among hematopoietic cell transplantation recipients: A global perspective. Biol Blood Marrow Transplant 2009; 15:1143-238.

11. Maertens J, Frere P, Lass-Florl C, Heinz W, Cornely O. 2007 update of the ECIL-1 guidelines for antifungal prophylaxis in leukemia patients, including allogeneic HSCT recipients. <www.leukemianet.org/content/home/> (Accessed August 26, 2009).

12. Ullmann AJ, Lipton JH, Vesole DH, et al. Posaconazole or fluconazole for prophylaxis in severe graft-versus-host disease. N Engl J Med 2007;356:335-47.

13. Keating GM. Posaconazole. Drugs 2005;65:1553-67.

14. Walsh TJ, Raad I, Patterson TF, et al. Treatment of invasive aspergillosis with posaconazole in patients who are refractory to or intolerant of conventional therapy: An externally controlled trial. Clin Infect Dis 2007:44:2-12.

15. Raad II, Hachem RY, Herbrecht R, et al. Posaconazole as salvage treatment of invasive fusariosis in patients with underlying hematologic malignancy and other conditions. Clin Infect Dis 2006;42:1398-403.

16. Cornely OA, Vehreschild JJ, Ruping MJGT. Current experience in treating invasive zygomycosis with posaconazole. Clin Microbiol Infect 2009; 15:77-81.

17. Noxafil ${ }^{\circledR}$ (posaconazole) oral suspension. 2009. Kenilworth, NJ, Schering Corporation.

18. Noxafil ${ }^{\circledR} 40 \mathrm{mg} / \mathrm{ml}$ oral suspension [summary of product characteristics]. 2010. Brussels, Belgium, SP Europe. <www.medicines.org.uk/emc/medicine/17339> (Accessed July 14, 2009).

19. Canadian Agency for Drugs and Technology in Health. Cedac final recommendation on reconsideration reasons for recommendations. $<$ www.cadth.ca/media/cdr/complete/cdr_complete_Spriafil_ January-30-2008.pdf> (Accessed November 12, 2009).

20. Cornely OA, Maertens J, Winston DJ, et al. Posaconazole vs. fluconazole or itraconazole prophylaxis in patients with neutropenia. N Engl J Med 2007;356:348-59.

21. O'Sullivan AK, Pandya A, Papadopoulos G, et al. Costeffectiveness of posaconazole versus fluconazole or itraconazole in the prevention of invasive fungal infections among neutropenic patients in the United States. Value Health 2009;12:666-73.

22. Collins CD, Ellis JJ, Kaul DR. Comparative cost-effectiveness of posaconazole versus fluconazole or itraconazole prophylaxis in patients with prolonged neutropenia. Am J Health Syst Pharm 2008;65:2237-43.

23. Stam WB, O'Sullivan AK, Rijnders B, et al. Economic evaluation of posaconazole versus standard azole prophylaxis in high risk neutropenic patients in the Netherlands. Eur J Haematol 2008;81:467-74.

24. Statistics Canada: Cancer survival statistics 1992-2000. <http:// cansim2.statcan.gc.ca/cgi-win/cnsmcgi.pgm?Lang $=$ E\&AS_Sort $=0$ $\&$ ChunkStart $=1 \&$ ChunkSize $=25 \&$ Result Template $=\% 2 F$ StuEtu\%2FStu-Etu6\&AS_Action $=$ Find\&AS_Theme $=-1 \& A S_{-}$ Date $=. \& A S \_S e r=. \& A S \_$Auth $=. \& A S \_U n i v=6 \& A S \_S r c h=$ cance $\mathrm{r}+$ survival+statistics\&AS_Btn=Search $>($ Accessed October 22, 2009).

25. National Cancer Institute. SEER cancer statistics review 1975-2003. $<$ http://seer.cancer.gov/csr/1975_2003/> (Accessed July 14, 2009).

26. Ontario Case Costing Initiative. Costing Analysis Tool (CAT). 2007/2008 [updated February 2010]. <www.occp.com/> (Accessed February 21, 2011).

27. Rotstein C, Bow EJ, Laverdiere M, et al. Randomized placebocontrolled trial of fluconazole prophylaxis for neutropenic cancer patients: Benefit based on purpose and intensity of cytotoxic therapy. Clin Infect Dis 1999;28:331-40.

28. Scottish Medicines Consortium. <www.scottishmedicines. org.uk/smc/servlet/controller?p_service=Content.show\&p applic $=C C C \& p C o n t e n t I D=5346>($ Accessed December 11, 2009). 
29. Australian Government Departments of Health and Ageing. Public summary documents by product: Posaconazole, oral suspension, 40 mg per ml, $105 \mathrm{ml}$, Noxafil ${ }^{\circledR}$. <www.health.gov.au/internet/main/ publishing.nsf/Content/pbac-psd-posaconazole-mar08/> (Accessed December 11, 2009).

30. Glasmacher A, Prentice A, Gorschluter M, et al. Itraconazole prevents invasive fungal infections in neutropenic patients treated for hematologic malignancies: Evidence from a meta-analysis of 3,597 patients. J Clin Oncol 2003;21:4615-26.

31. Marr KA, Crippa F, Leisenring W, et al. Itraconazole versus fluconazole for prevention of fungal infections in patients receiving allogeneic stem cell transplants. Blood 2004;103:1527-33.

32. Winston DJ, Maziarz RT, Chandrasekar PH, et al. Intravenous and oral itraconazole versus intravenous and oral fluconazole for longterm antifungal prophylaxis in allogeneic hematopoietic stem-cell transplant recipients. A multicenter, randomized trial. Ann Intern Med 2003;138:705-13.
33. Glasmacher A, Cornely O, Ullmann AJ, et al. An open-label randomized trial comparing itraconazole oral solution with fluconazole oral solution for primary prophylaxis of fungal infections in patients with haematological malignancy and profound neutropenia. J Antimicrob Chemother 2006;57:317-25.

34. Dasbach EJ, Davies GM, Teutsch SM. Burden of aspergillosisrelated hospitalizations in the United States. Clin Infect Dis 2000;31:1524-8.

35. Wilson LS, Reyes CM, Stolpman M, Speckman J, Allen K, Beney J. The direct cost and incidence of systemic fungal infections. Value Health 2002;5:26-34.

36. Kantarjian H, Beran M, Cortes J, et al. Long-term follow-up results of the combination of topotecan and cytarabine and other intensive chemotherapy regimens in myelodysplastic syndrome. Cancer 2006;106:1099-109.

37. Guidelines for the economic evaluation of health technologies. Ottawa, Canada: Canadian Agency for Drugs and Technologies in Health; 2006 March Report No: 3rd edn. 


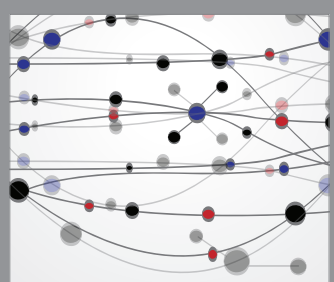

The Scientific World Journal
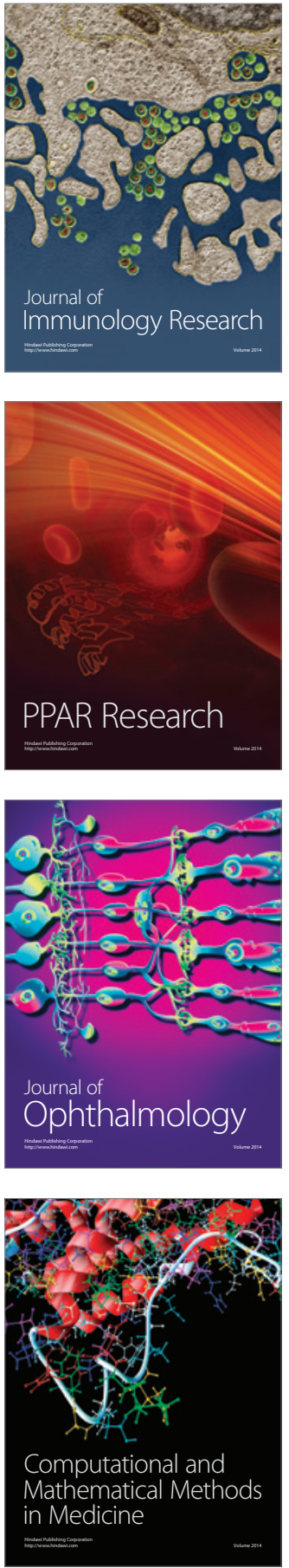

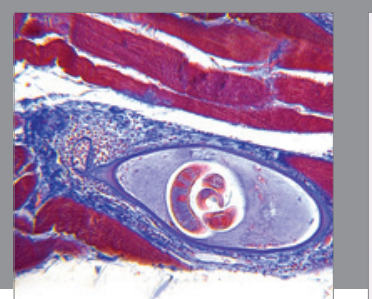

Gastroenterology Research and Practice

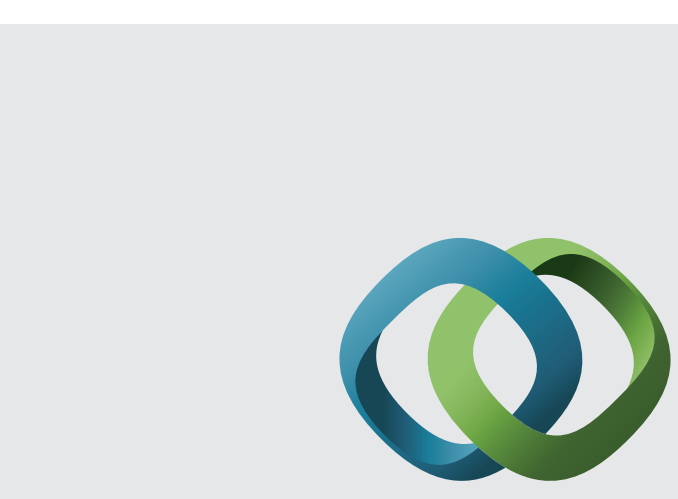

\section{Hindawi}

Submit your manuscripts at

http://www.hindawi.com
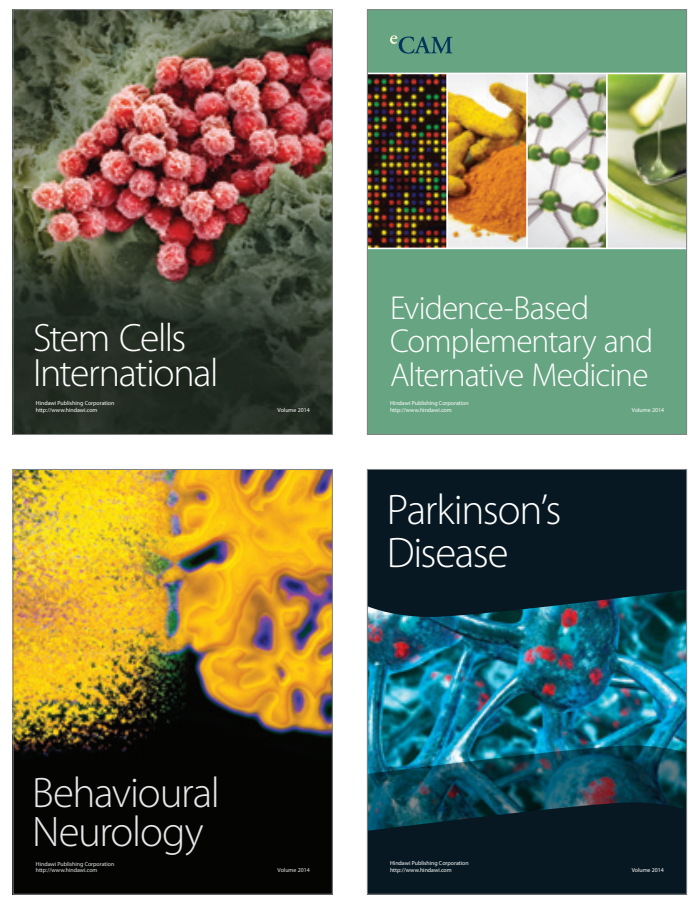
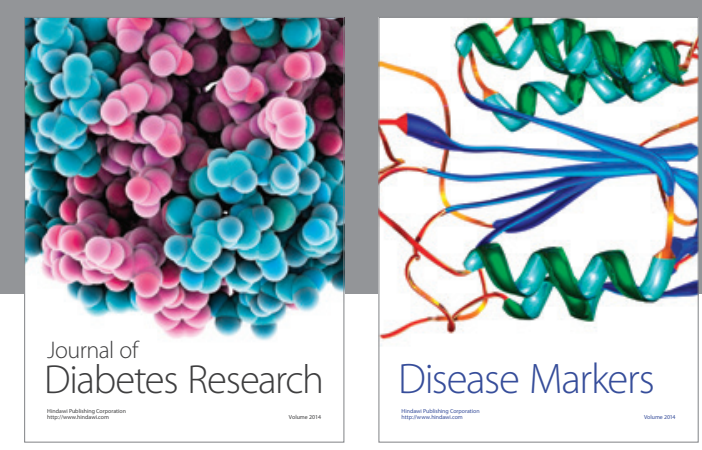

Disease Markers
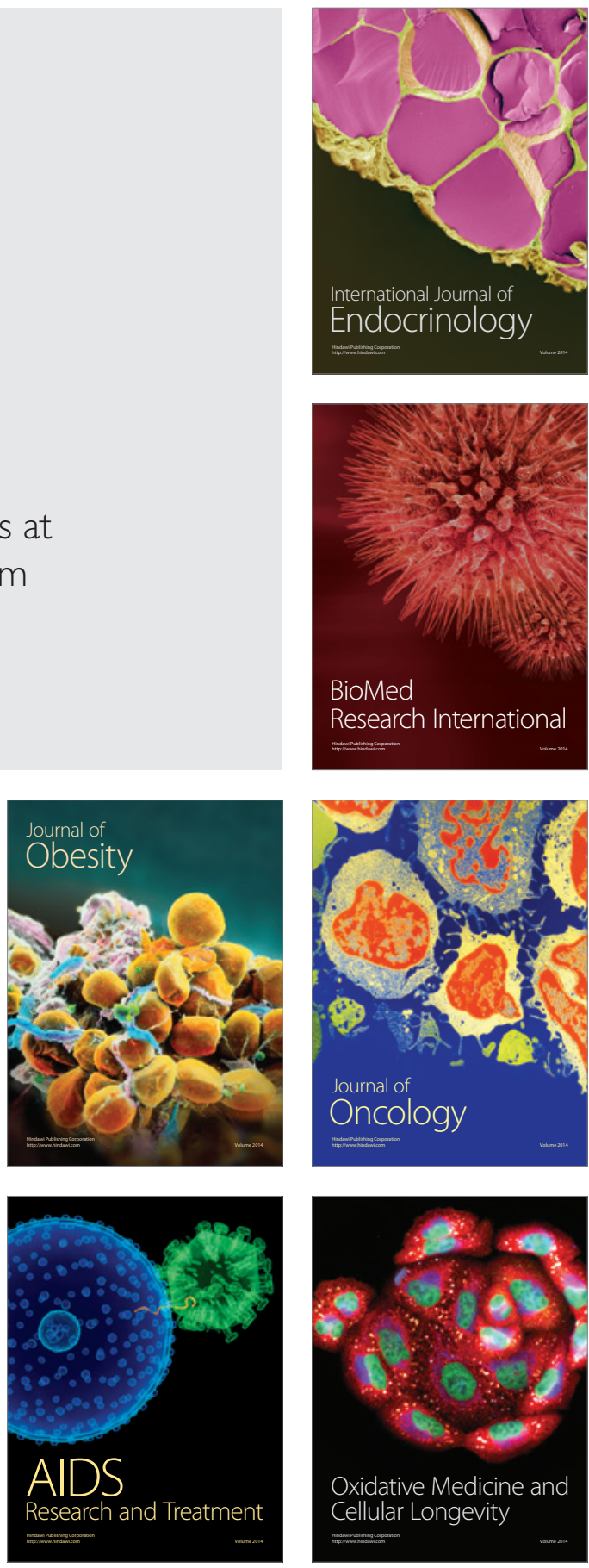